\title{
The Comparison of Prediction Model of Lowering Rate Road Surface Damage Between RCI and SDI Method in Lumajang Regency
}

\author{
(Perbandingan Model Prediksi Penurunan Tingkat Kerusakan Permukaan Jalan Metode \\ $\mathrm{RCI}$ dan Metode SDI di Kabupaten Lumajang)
}

\author{
Yulianata Halim Afandi*), Dewi Junita Koesoemawati, Akmad Hasanuddin \\ Jurusan Teknik Sipil, Fakultas Teknik, Universitas Jember \\ Jl. Kalimantan 37, Jember 68121
}

\section{ABSTRACT}

Sand mining was a non-metal mineral commodity which had very good quantity and quality for building materials in Lumajang district. It was found in lava routes or large rivers in the Pasirian sub-district at Lumajang district. The location of sand material was in a river that passes through the regency road. This result was in many road damage in the district area. The efforts to overcome the damage that often occurs on roads in Pasirian sub-district included road improvement activities supported by road surface surveys using the RCI method which has been used in reporting basic road conditions. This study aim conducted of comparing the RCI survey method and predicting a decline in the last 3 (three) years to 2021 with the SDI survey method in 2021 . The value being compared was in good condition from the overall report. After predicting the reduction in road damage with the regression method from the survey results of road conditions in $2017-2020$ with the RCI method, the equation Y $=-11,807 \times 2021+23868$ has a prediction of a decrease of $6,053 \%$. After carrying out a survey of road conditions used the SDI method in 2021 on district roads in the Pasirian sub-district. There was an $8 \%$ decrease in good conditions. On the road in the Pasirian regency area, the decrease in the condition of the road surface was due to one of the factors being the excessive traffic load (over loaded) which causes a steady condition of the sections around the sand mine in the Pasirian sub-district.

Pertambangan pasir di kabupaten Lumajang merupakan komoditi mineral bukan logam yang mempunyai kuantitas dan kualitas yang sangat baik untuk bahan bangunan dan banyak terdapat di jalur lahar atau sungai besar di daerah kecamatan Pasirian kabupaten Lumajang. Lokasi pengambilan material pasir tersebut terletak di sungai yang melewati ruas jalan kabupaten dan ini banyak mengakibatkan kerusakan jalan di wilayah kecamatan tersebut. Upaya mengurangi kondisi jalan yang tidak mantab yang sering terjadi pada ruas jalan di kecamatan Pasirian tersebut diantaranya dilakukan kegiatan peningkatan jalan didukung dengan survei permukaan jalan dengan metode RCI yang selama ini dipakai dalam pelaporan data dasar kondisi jalan, pada tahun 2021 lewat Kementerian PUPR dengan dana khusus infrasturktur jalannya dan metode survei SDI yang dipersyaratkan untuk kegiatan pemeliharaan jalan dan peningkatan jalan. Dengan adanya perubahan diatas maka diadakan penelitian dengan tujuan membandingkan metode survei menggunakan metode RCI serta dilakukan prediksi penurunan di 3 (tiga) tahun terakhir sampai tahun 2021 dengan metode survei menggunakan SDI di tahun 2021, nilai yang dibandingkan pada kondisi baik dari laporan keseluruhan. Setelah dilakukan prediksi penurunan kerusakan jalan dengan metode regresi dari kegiatan survei kondisi jalan tahun 2017 - 2020 dengan jenis survey kondisi jalan RCI didapatkan persamaan Y $=-11.807$ x $2021+23868$ prediksi penurunan sebesar 6,053\% dan setelah dilaksanakan survei kondisi jalan dengan metode SDI di tahun 2021 di ruas jalan kabupaten di wilayah kecamataan Pasirian didapatkan penurunan 8\% pada kondisi baik. Di ruas jalan kabupaten wilayah pasirian, penurunan kondisi permukaan jalan ini dikarenakan salah satu faktornya beban lalu - lintas yang berlebihan (over loaded) yang menyebabkan kondisi mantap dari ruas sekitar tambang pasir di kecamatan pasirian.

Keywords: reduction, road damage, RCI, SDI. 


\section{PENDAHULUAN}

Pengertian pemeliharaan jalan adalah kegiatan penanganan jalan berupa pencegahan, perawatan dan perbaikan yang diperlukan untuk mempertahankan kondisi jalan agar tetap berfungsi secara optimal melayani lalu - lintas sehingga umur rencana dapat dilalui.

Jalan di Kabupaten Lumajang adalah 368 ruas jalan dengan jumlah panjangnya $1.109 \mathrm{~km}$ berada di 21 kecamatan sesuai dengan Surat Keputusan Bupati Nomor: 188.45 / 89 / 427.12 / 2017 tentang Penetapan Ruas - Ruas Jalan. Menurut fungsi jalan dan statusnya sebagai Jalan Kabupaten dengan kondisi Lumajang jalan mantab dari tahun 2017 sampai tahun 2019 terus menurun sedangkan anggaran di Dinas Pekerjaan Umum dan Tata Ruang tiap tahun bertambah. Untuk target Rencana Strategis (Renstra) SKPD, setiap tahunnya selalu tidak memenuhi target, dengan penelitian lain oleh Suherman [1] Studi persamaan korelasi antara ketidakrataan permukaan jalan dengan kondisi jalan Novia dkk.[2]. Analisis kondisi fungsional jalan dengan metode PSI dan RCI serta prediksi sisa umur perkerasan jalan dengan kesimpulan prediksi sisa umur perkerasan dengan metode PCI dan RCI perlu dilengkapi dengan data volume lalu lintas. Dan Ing [3], tentang penelitian tentang analisis kondisi permukaan perkerasan jalan Lemahneudeut dengan metode PCI dan RCI.

Tujuan penelitian adalah mengamati kerusakan di ruas jalan wilayah Kecamatan Pasirian yang dilewati angkutan pasir dengan metode survei RCI dan dibandingkan dengan metode SDI serta melakukan prediksi penurunan kondisi permukaan jalan selama 3 (tiga) tahun agar mendapatkan nilai akurat terkait efek dari angkutan tambang pasir yang melintas di jalan kabupaten di wilayah Kecamatan Pasirian.

\section{METODE PENELITIAN}

\section{Lokasi Penelitian}

Kegiatan-kegiatan yang dilakukan di dalam studi pendahuluan ini pada dasarnya adalah untuk membandingkan metode survei kondisi jalan dengan Road Condition Index (RCI) pada tahun tahun 2018 sampai 2020 yang dilakukan pada kawasan pertambangan pasir wilayah Kecamatan Pasirian. Kemudian dilakukan analisi regresi untuk prediksi penurunan kondisi perkerasannya di tahun 2021 dan dibandingkan dengan cara survei kondisi jalan dengan cara SDI (Surface Distress Index), yang dilakukan tahun 2021 Pandangan dari studi pendahuluan ini adalah sebagai berikut:

a. 9 ruas jalan di wilayah kecamatan Pasirian yang termasuk jalur truk pasir tanpa dilakukan pemeliharaan rutin jalan di tahun setelahnya;

b. 9 ruas tersebut data LHR (Lalu Lintas Harian Rata2x).

Pustaka atau literatur referensi sebagai acuan landasan teori diperoleh dari beberapa textbook yang berkaitan dengan metode survei kondisi jalan RCI dan SDI.

\section{Sistem Jaringan Jalan}

Berdasarkan sistem jaringannya, jalan dikelompokkan ke dalam jaringan jalan primer dan jaringan jalan sekunder, sedangkan berdasarkan peranannya, jalan dikelompokkan kedalam jalan arteri, jalan kolektor, dan jalan lokal.

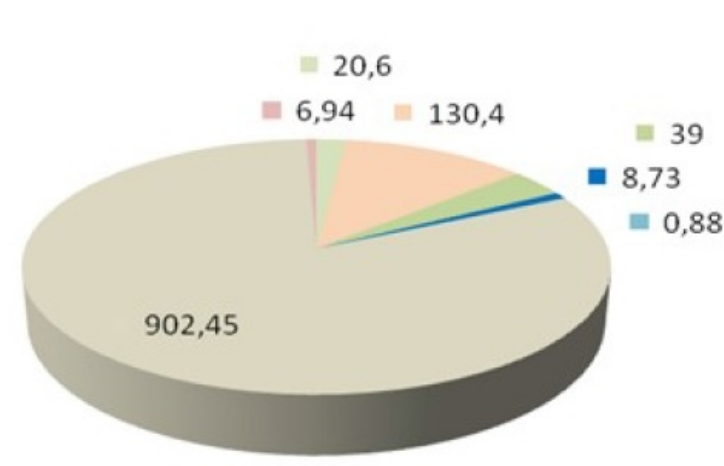

(Sumber: SK Jalan Kab. Lumajang, 2017)

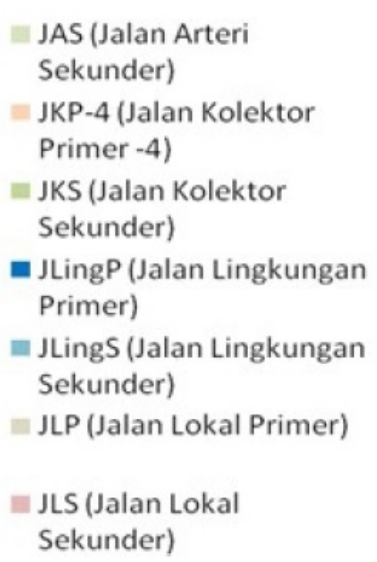

Gambar 1. Panjang jaringan jalan 


\section{Faktor Kerusakan Jalan}

Menurut Sukirman kerusakan pada konstruksi perkerasan jalan dapat disebabkan oleh beberapa faktor sebagai berikut:

1. Lalu lintas, yang dapat berupa penambahan beban dan pengulangan beban;

2. Air, yang dapat berasal dari alam berupa air hujan, dan naiknya air akibat sifat kapilaritas serta sistem drainase yang kurang baik ;

3. Material konstruksi perkerasan, pemilihan material yang tidak sesuai keadaan atau dapat pula disebabkan oleh sistem pengolahan yang tidak baik;

4. Iklim, Indonesia beriklim tropis dimana suhu udara dan curah hujan umumnya tinggi yang merupakan salah satu penyebab kerusakan jalan;

5. Kondisi tanah dasar yang tidak stabil, faktor ini kemungkinan disebabkan oleh sistem pekerjaan kurang baik atau dapat juga disebabkan oleh sifat tanah dasarnya yang ekpansif;

6. Proses pekerjaan pemadatan lapisan di atas tanah dasar yang kurang optimal.

\section{Jenis Kerusakan Perkerasan Lentur}

Hardiyatmo [4], menyatakan bahwa jenis- jenis kerusakan perkerasan jalan lentur dapat diklasifikasikan: deformasi, retak (crack), kerusakan di pinggir perkerasan, kerusakan tekstur permukaan jalan, lubang (potholes), tambalan dan tambalan galian utilitas (patching and utility cut patching). [4]

\section{Deformasi}

Deformasi adalah perubahan permukaan jalan dari profil aslinya (sesudah pembangunan). Mengacu pada Austroads [5] dan Shahin [6], beberapa tipe deformasi perkerasan lentur adalah:
a. Bergelombang (Corrugation)
b. Alur (Rutting)
c. Ambles (Depression)
d. Sungkur (Shoving)
e. Mengembang (Swell)
f. Benjol dan penurunan (Bump and sags)

\section{Retak (crack)}

Retak yang terjadi pada permukaan jalan dapat dibedakan

1. Retak halus

2. Retak kulit buaya

3. Retak Pinggir
4. Retak sambungan bahu dan perkerasan

5. Retak susut

6. Retak slip

\section{Kerusakan di Pinggir Perkerasan}

Kerusakan di pinggir perkerasan adalah retak yang terjadi di sepanjang pertemuan antara permukaan perkerasan aspal dan bahu jalan, lebih-lebih bila bahu jalan tertutup (unsealed). Kerusakan ini terjadi secara lokal atau bahkan bisa memanjang di sepanjang jalan, dan sering terjadi di salah satu bagian jalan atau sudut. Mengacu pada Austroads [5], kerusakan di pinggir perkerasan aspal dapat dibedakan menjadi:

a. Retak pinggir (edge eracking) pinggir pecah (edge breaks). Retak pinggir biasanya dan terjadi sejajar dengan pinggir perkerasan dan berjarak 0,3-0,6 $\mathrm{m}$ dari pinggir.

b. Pinggir turun (edge drop-off) merupakan beda evalasi antara pinggir perkerasan dan bahu jalan.

\section{Kerusakan Tekstur Permukaan Jalan}

Adanya kerusakan yang tidak segera dilakukan perbaikan dapat menyebabkan kualitas sruktur perkerasan menurun. Kerusakan pada tekstur permukaan aspal dibedakan menjadi:

1. Butiran lepas (raveling)

Butiran lepas yaitu permukaan perkerasan aspal melalui pelepasan partikel agregrat yang berkelanjutan yang mengalami kehancuran, berawal dari permukaan perkerasan menuju ke bawah atau dari pinggir ke dalam.

2. Kegemukan (bleeding)

Kerusakan ini disebabkan oleh hasil dari pengikat aspal yang melebihi batas, yang beralih ke atas permukaan. Dengan persentasi aspal melebihi batas atau kadar udara yang rendah pada komposisi menyebabkan bleeding.

3. Agregrat licin (polished aggregate)

Agregat licin merupakan kerusakan permukaan pada atas perkerasan yang licin diakibatkan ausnya agregat di permukaan.

4. Terkelupas (delamination)

Kerusakan ini disebabkan terkelupasnya lapisan yang aus pada permukaan perkerasan. Solusi dalam kerusakan ini yaitu tamabahan hamparan lapis (overlay).

5. Stripping 
Stipping disebut keadaan dimana lenyapnya agregat kasar pada bahan penutup yang dilakukan penyemprotan, yang mengakibatkan kontak langsung antara bahan pengikat dengan ban. Solusi untuk mencegah kerusakan ini yaitu penghamparan lapis tipis tambahan (overlay).

\section{Lubang (potholes)}

Lubang merupakan permukaan perkerasan yang berongga yang disebabkan lapisan aus dan material lapis pondasi (base) yang menghilang. Pertumbuhan kerusakan ini akan dipercepat dengan besertanya air dalam lubang.

\section{Tambalan dan Tambalan Galian Ultilitas (patching dan utility cut patching)}

Tambahan (patching) merupakan penutup dalam pekerjaan perkerasan setelah dilakukan perbaikan. Tambalan kerusakan perkerasan dapat diikuti dengan hilangnya kenyamanan dalam berkendara yaitu gagal secara fungsional atau rusaknya struktur perkerasan.

\section{Analisis Regresi}

Untuk prediksi penurunan digunakan analisis regresi dimana prediksi ini dibagi menjadi dua jenis variabel yaitu variabel prediktor atau bebas dan variabel respon atau tidak bebas. Variabel prediktor yaitu variabel yang tersedia. Variabel respon adalah variabel akibat variabel prediktor. Untuk kepentingan analisis, variabel prediktor dinyatakan dengan X1, $\mathrm{X} 2, \ldots \ldots, \mathrm{Xn}(\mathrm{n} \geq 1)$, untuk variabel respon dinyatakan dengan Y. Beberapa bentuk regresi yang ada di antaranya dengan persamaan:

regresi linier;

$y=a+b$

regresi linier berganda;

$y=a 0+a 1 X 1+a 2 X 2$

regresi non linier;

Parabola Kuadratik

$Y=a 0+a 1 X+a 2 X^{2}$

Parabola Kubik

$Y=a+c^{2}+d^{3}$

Eksponen

$Y=\ddot{a}$

\section{Variabel Studi}

Variabel yang dipakai pada penelitian ini terdiri dari kondisi jalan dengan SDI sesuai Peraturan Menteri Pekerjaan Umum dan Perumahan Rakyat No. 15 tahun 2007 [7].

Untuk menetapkan nilai di tinjau dengan dasar kondisi secara penglihatan dan jenis permukaan pada 9 ruas jalan di kecamatan pasirian

1. Pasirian - bades

2. Bades - Gondoruso

3. Gondoruso - Dampar

4. Dampar - Kaligede

5. Gesang - Tumpeng

6. Madurejo - Sememu

7. Bades - Kalibendo

8. Gondoruso - Jugosari

9. Lingkar Watu udel

Tabel 1. Penetapan Nilai RCI

\begin{tabular}{|c|c|c|c|}
\hline No & Jenis Permukaan & Kondisi Secara Penglihatan & $\begin{array}{l}\text { Nilai } \\
\text { RCI }\end{array}$ \\
\hline 1 & $\begin{array}{c}\text { Jalan tanah dengan drainase buruk, dan jenis permukaan } \\
\text { yang tidak diurus. }\end{array}$ & Tidak dapat diakses & $0-2$ \\
\hline 2 & $\begin{array}{c}\text { Semua jenis perkerasan yang tidak diurus melebihi 4-5 } \\
\text { Tahun atau lebih }\end{array}$ & $\begin{array}{l}\text { Seluruh daerah perkerasan mengalami rusak } \\
\text { berat dengan banyak lubang }\end{array}$ & $2-3$ \\
\hline 3 & P.M lama dst. & Banyak lubang dan rusak yang bergelombang & $3-4$ \\
\hline 4 & P.M setelah penggunaan 2 tahun, lastabum lama & $\begin{array}{c}\text { Agak rusak, sedikit lubang dengan permukaan } \\
\text { yang tidak rata }\end{array}$ & $4-5$ \\
\hline 5 & $\begin{array}{l}\text { Pen, macadam baru, lasbutag, lastasbum baru setelah } \\
\text { pemakaian } 2 \text { tahun }\end{array}$ & $\begin{array}{c}\text { Cukup atau sedikit sekali perkerasan berlubang, } \\
\text { namu permukaanagak tidak rata }\end{array}$ & $5-6$ \\
\hline 6 & $\begin{array}{l}\text { Lapisan hot mix lama yang tipis, lasbutag dan latasbum } \\
\text { baru dengan penggunaan setelah } 2 \text { tahun }\end{array}$ & 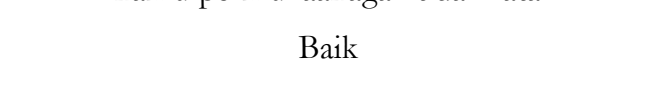 & $6-7$ \\
\hline 7 & Hot mix denga umur 2 tahun, hot mix tipis diatas P.M & Pada umumnya rata, namun sangat baik & $7-8$ \\
\hline 8 & $\begin{array}{c}\text { Hot mix baru (laston,lataston) (Peningkatan dan } \\
\text { penggunaanya melebihi } 1 \text { lapis) }\end{array}$ & Teratur dan sangat rata & $8-9$ \\
\hline
\end{tabular}

(Sumber: Permen PU no 13 Tahun 2011 [8]) 


\section{HASIL DAN PEMBAHASAN}

Berikut hasil survei yang dilakukan dengan melakukan metode RCI di ruas tanpa pemeliharaan rutin jalan selama 3 tahun:

1. Tingkat penurunan kerusakan dengan metode survei kondisi jalan RCI yang mengalami penurunan tidak terlalu ekstrem

a. Ruas jalan Pasirian - Bades

Selama tiga tahun tanpa kegiatan pemeliharaan dan diprediksi di tahun 2021 selisih 6,3 di keadaan kondisi baik dengan metode analisa regresi persamaannya $=2.375 x+4890.4$ artinya setiap penambahan tahun dimasukkan kehuruf $\mathrm{x}$ akan mendapatkan nilai kondisi baik

b. Ruas jalan Bades - Gondoruso Keadaan kondisi baik dengan metode analisa regresi persamaannya $=-3.125 x+6404.2$ artinya setiap penambahan tahun dimasukkan kehuruf $\mathrm{x}$ akan mendapatkan nilai kondisi baik

c. Ruas Jalan Gondoruso - Dampar

Selama tiga tahun tanpa kegiatan pemeliharaandan di prediksi di tahun 2021 selisih 6,22 di keadaan kondisi baik dengan metode analisa regresi persamaannya $=$ $2.3469 x+4783.5$ artinya setiap penambahan tahun dimasukkan kehuruf $\mathrm{x}$ akan mendapatkan nilai kondisi baik dengan data LHR 41.03

d. Ruas jalan Dampar - Kaligede Selama tiga tahun tanpa kegiatan pemeliharaan dan diprediksi di tahun 2021 selesih 86,84 di keadaan kondisi baik dengan metode analisa regresi persamaannya $=-29.038 x+58628$ artinya setiap penambahan tahun dimasukkan kehuruf $\mathrm{x}$ akan mendapatkan nilai kondisi baik dengan data LHR 48.77

e. Ruas jalan Gesang - Tumpeng
Selama tiga tahun tanpa kegiatan pemeliharaan dan diprediksi di tahun 2021 selisih 75 di keadaan kondisi baik dengan metode analisa regresi persamaannya $=y=-25 x+50475$ artinya setiap penambahan tahun dimasukkan kehuruf $\mathrm{x}$ akan mendapatkan nilai kondisi baik dengan data LHR 8.36

f. Ruas jalan Madurejo - Sememu Selama tiga tahun tanpa kegiatan pemeliharaan dan diprediksi di tahun 2021 selisih 50 di keadaan kondisi baik dengan metode analisa regresi persamaannya $=y=-13.75 x+27758$ artinya setiap penambahan tahun dimasukkan ke huruf $\mathrm{x}$ akan mendapatkan nilai kondisi baik dengan data LHR 39.72

g. Ruas jalan Bades - Kalibendo

Selama tiga tahun tanpa kegiatan pemeliharaan dan diprediksi di tahun 2021 selisih 28 di keadaan kondisi baik dengan metode analisa regresi persamaannya $=\mathrm{y}=-5,3617 \mathrm{x}+10874$ artinya setiap penambahan tahun dimasukkan ke huruf $\mathrm{x}$ akan mendapatkan nilai kondisi baik dengan data LHR 85,93

h. Ruas jalan Bades - Gondoruso

Selama tiga tahun tanpa kegiatan pemeliharaan dan diprediksi di tahun 2021 selisih 54 di keadaan kondisi baik dengan metode analisa regresi persamaannya $=y=-10,678 x+21562$ artinya setiap penambahan tahun dimasukkan ke huruf $\mathrm{x}$ akan mendapatkan nilai kondisi baik dengan data LHR 117,49

i. Ruas jalan Lingkar Watu Udel

Selama tiga tahun tanpa kegiatan pemeliharaan dan diprediksi di tahun 2021 selisih 147 di keadaan kondisi baik dengan metode analisa regresi persamaannya $=\mathrm{y}=-29,333 \mathrm{x}+59235$ artinya setiap penambahan tahun dimasukkan ke huruf $\mathrm{x}$ akan mendapatkan nilai kondisi baik dengan data LHR 1,00. 


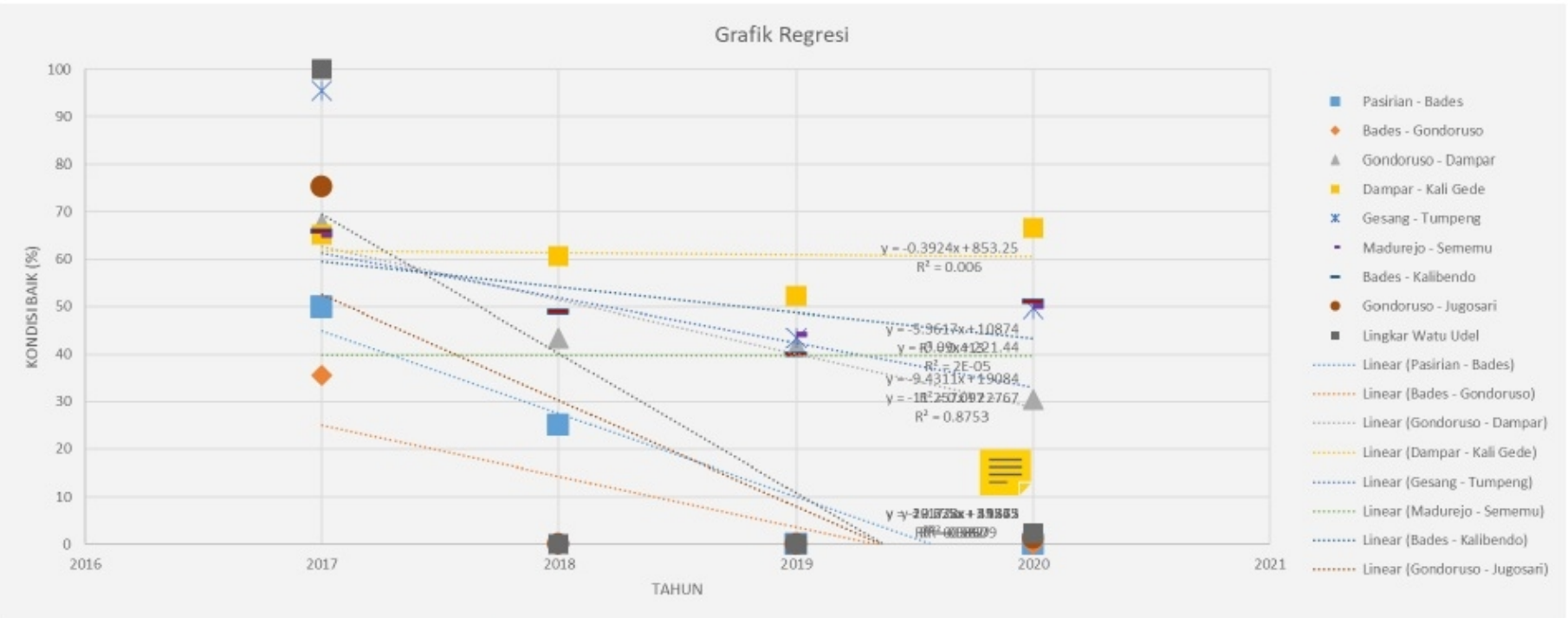

(Sumber: Dokumen Penelitian, 2021)

Gambar 2. Grafik Regresi Penurunan

Tabel 2. Penentuan Nilai SDI

\begin{tabular}{ll}
\hline Nilai SDI & Kondisi SDI \\
\hline$<50$ & Baik \\
$50-100$ & Sedang \\
$100-150$ & Rusak Ringan \\
$>150$ & Rusak Berat \\
\hline
\end{tabular}

(Sumber: Dokumen Penelitian,2021

Tabel 3. Hasil Perhitungan SDI

\begin{tabular}{|c|c|c|c|c|c|c|c|c|c|c|c|c|c|c|}
\hline \multirow{2}{*}{$\begin{array}{l}\text { No } \\
\text { Ruas }\end{array}$} & \multirow{2}{*}{ Nama Ruas } & \multirow{2}{*}{$\begin{array}{c}\text { Panj } \\
\text { ang } \\
\text { Rua } \\
\text { s }\end{array}$} & \multicolumn{2}{|c|}{ Baik } & \multicolumn{2}{|c|}{ Sedang } & \multicolumn{2}{|c|}{$\begin{array}{l}\text { Rusak } \\
\text { Ringan }\end{array}$} & \multicolumn{2}{|c|}{$\begin{array}{c}\text { Rusak } \\
\text { Berat }\end{array}$} & \multicolumn{2}{|c|}{ Mantap } & \multicolumn{2}{|c|}{$\begin{array}{c}\text { Tidak } \\
\text { Mantap }\end{array}$} \\
\hline & & & $M^{\prime}$ & $\%$ & M' & $\%$ & M' & $\%$ & $M^{\prime}$ & $\%$ & M' & $\%$ & $M^{\prime}$ & $\%$ \\
\hline 015 & $\begin{array}{l}\text { Pasirian- } \\
\text { Bades }\end{array}$ & 800 & 200 & $25.00 \%$ & 200 & $25.00 \%$ & 400 & $50.00 \%$ & 0 & $0.00 \%$ & 400 & $50 \%$ & 400 & $50 \%$ \\
\hline 016 & $\begin{array}{c}\text { Bades- } \\
\text { Gondoruso }\end{array}$ & 5900 & 100 & $1.69 \%$ & 0 & $0.00 \%$ & 2400 & $40.68 \%$ & 2400 & $57.63 \%$ & 100 & $1.69 \%$ & 5800 & $98.31 \%$ \\
\hline 017 & $\begin{array}{c}\text { Gondoruso- } \\
\text { Dampar }\end{array}$ & 4600 & 2400 & $52.17 \%$ & 600 & $13.04 \%$ & 600 & $13.04 \%$ & 1000 & $21.74 \%$ & 3000 & $65.22 \%$ & 1600 & $34.78 \%$ \\
\hline 018 & $\begin{array}{l}\text { Dampar-Kali } \\
\text { Gede }\end{array}$ & 6600 & 420 & $63.64 \%$ & 1200 & $18.18 \%$ & 1000 & $15.15 \%$ & 200 & $3.03 \%$ & 5400 & $81.82 \%$ & 1200 & $18.18 \%$ \\
\hline 049 & $\begin{array}{l}\text { Gesang- } \\
\text { Tumpeng }\end{array}$ & 6750 & 5150 & $76.30 \%$ & 800 & $11.85 \%$ & 600 & $8.89 \%$ & 200 & $2.96 \%$ & 5950 & $88.15 \%$ & 800 & $11.85 \%$ \\
\hline 187 & $\begin{array}{l}\text { Madurejo- } \\
\text { Semeru }\end{array}$ & 4000 & 3000 & $75.00 \%$ & 0 & $0.00 \%$ & 200 & $5.00 \%$ & 800 & $20.00 \%$ & 300 & $75.00 \%$ & 1000 & $25.00 \%$ \\
\hline 191 & $\begin{array}{c}\text { Bades- } \\
\text { Kalibendo }\end{array}$ & 2350 & 1350 & $57.45 \%$ & 800 & $34.04 \%$ & 200 & $8.51 \%$ & 0 & $0.00 \%$ & 2150 & $91.49 \%$ & 200 & $8.51 \%$ \\
\hline 195 & $\begin{array}{c}\text { Gondoruso- } \\
\text { Jugosari }\end{array}$ & 4050 & 4050 & $0.00 \%$ & 0 & $0.00 \%$ & 0 & $0.00 \%$ & 0 & $0.00 \%$ & 4050 & $100.00 \%$ & 0 & $0.00 \%$ \\
\hline 196 & $\begin{array}{c}\text { Lingkar } \\
\text { Watu-Udel }\end{array}$ & 2450 & 2450 & $0.00 \%$ & 0 & $0.00 \%$ & 0 & $0.00 \%$ & 0 & $0.00 \%$ & 2450 & $100.00 \%$ & 0 & $0.00 \%$ \\
\hline & Rata-rata & & & $61.25 \%$ & & $11.33 \%$ & & $15.70 \%$ & & $11.71 \%$ & & $72.60 \%$ & & $27.40 \%$ \\
\hline
\end{tabular}

(Sumber: Dokumen Penelitian, 2021) 
Survei dengan menggunakan metode SDI di survei yang dilakukan untuk jalan di kecamatan pasirian di ruas yang sering dilalui truk pasir dengan tanpa pemeliharaan 9 (Sembilan) ruas yang mengalami penurunan sebesar $8 \%$ petunjuk teknis nya sesuai dengan Permen PU No. 15/PRT/M/2007 [7] tentang Pedoman Survei Kondisi Jalan Tanah atau Kerikil dan kondisi rinci jalan beraspal.

\section{KESIMPULAN}

Berdasarkan hasil analisis dan pembahasan bahwa dengan dilakukan survei kondisi jalan di ruas jalan yang tidak dilakukan pemeliharaan rutin di kecamatan Pasirian dengan traffic angkutan pasir selama 3 tahun angka kemantaban jalan di prediksi mengalami penurunan rata - rata $16 \%$ per tahun 2021; lalu dilakukan perbandingan dengan dengan survei kondisi ruas jalan yang dilakukan di 9 (Sembilan) ruas di survei menggunakan metode SDI sesuai ketentuan DAK dari Kementerian Pekerjaan Umum mengalami penurunan rata - rata $8 \%$ dan dengan perbandingan tersebut untuk survei SDI sesuai Permen PUPTR No.15 tahun 2007 [7] dan survei metode RCI dengan SDI, SDI lebih obyektif karena form survei untuk penilainnya dilakukan langsung pengukurannya dan perhitungan terhadap kerusakan jadi lebih akurat Sedangkan metode survei RCI hanya menggunakan penilaian secara visual dari surveior saja sehingga lebih subyektif.

\section{DAFTAR PUSTAKA}

[1] Suherman, "Studi Persamaan Korelasi antara Ketidakrataan Permukaan Jalan dengan Indeks Kondisi Jalan Studi Kasus Ruas Jalan LabuanCibaliung," Journal Teknik Sipil, vol. 8, pp. 206-214, 2008.

[2] N. A. Nugraheni, A. Setiawan and Suryoto, "Analisis Kondisi Fungsional Jalan dengan Metode PSI dan RCI serta Prediksi Sisa Umur Perkerasan Jalan," Journal Matriks Teknik Sipil, vol. 6, pp. 105-119, 2018.

[3] T. L. Ing and S. Riana, "Analisis Kondisi Permukaan Perkerasan Jalan Pada Jalan Lemahneundeut dengan Metode PCI dan RCI," Jurnal Teknik Sipil, vol. 15, pp. 36-45, 2019.

[4] H. C. Hardiyatmo, Pemilihan Jalan Raya, Yogyakarta: Gajah Mada Press, 2007.
[5] Austroads, A Guide to the Visual Assesment of Pavement Condition, Sydney: Austroads, 1987.

[6] M. Y. Shahin, Pavement Management for Airport Roads, adn Parking lots, New York: Chapman \& Hill, 1994.

[7] Menteri. Pekerja. Umum, "Pedoman Survei Kondisi Jalan Tanah dan atau Kerikil dan Kondisi Rinci Jalan Beraspal untuk Jalan Antar Kota," No 15/PRT/M/2007.

[8] Menteri. Pekerja. Umum. Republik. Indonesia, "Tata Cara Pemeliharaan dan Penilikan Jalan," 2011.

[9] Direktorat. Jendral. Bina. Marga, "Panduan Pemilihan Teknologi Pemeilharaan Preventif Perkerasan Jalan," 2017. 